\title{
Internet Gaming Addiction: A Technological Hazard
}

\author{
Ankur Sachdeva," and Rohit Verma ${ }^{2}$ \\ ${ }^{1}$ Department of Psychiatry, ESIC Medical College and Hospital, Faridabad, India \\ ${ }^{2}$ Department of Psychiatry, All India Institute of Medical Sciences, New Delhi, India \\ *Corresponding author: Ankur Sachdeva, Department of Psychiatry, ESIC Medical College and Hospital, Faridabad, India. Tel: +91-9899528355, Fax: +91-1294156471, \\ E-mail:drankur.rml@gmail.com
}

Received 2015 January 14; Revised 2015 February 14; Accepted 2015 February 17.

\begin{abstract}
Introduction: The Internet is considered a beneficial tool in research, communication, and information. Still, its excessive and prolonged use has the potential of causing addiction. The presentation of this technological hazard may range from a mild socio-personal distress to a gross disorganization in behavior and self-care. No reported study on Internet gaming addiction is available from India.

Case Presentation: We reported a case of two brothers, diagnosed with Internet gaming addiction, who showed grossly disorganized behavior and severely compromised self-care. The condition was managed by pharmacological and non-pharmacological therapies, with sustained improvement after 6 months follow up.

Conclusions: Internet gaming addiction may cause severe personal, social, and occupational problems. Despite the range of severity and various presentations of this disorder, DSM-5 lacks the severity classifier. Early identification and management may result in complete recovery.
\end{abstract}

Keywords: Behavior, Addictive, Internet

\section{Introduction}

Rapid and extensive proliferation of the Internet has resulted in better opportunities for research, communication, and information. Useful to some extent, this modern day technological wonder has largely caused decline in physical and mental well-being owing to its potential for causing addiction in the form of pornography, excessive gaming, chatting for long hours, gambling, and online shopping.

Goldberg in 1995 introduced the term "Internet addiction" for pathological compulsive Internet use (1). Excessive Internet gaming has been described as a specific subtype of Internet addiction (2). According to some reports, up to $90 \%$ of American youngsters play video games and about $15 \%$ of them may be addicted (3). Internet gaming disorder has been placed in category III of DSM-5 (4). Still, it has not been classified under main disorders as adequate research-based evidence is lacking. The presentation of Internet gaming disorder may range from a mild socio-personal distress to a gross disorganization in behavior and self-care. However, the DSM-5 lacks the severity classifier. The understanding of Internet addiction is still in initial stages in Indian subcontinent. No reported studies on Internet gaming addiction are available from India. We report two brothers diagnosed with Internet gaming addiction, with grossly disorganized behavior and severely compromised self-care. We managed their problem with behavior therapy and fluoxetine.

\section{Case Presentation}

Messrs A and B were two unmarried brothers, belonging to a nuclear family of upper socioeconomic class of urban background of Delhi. Mr A is 19 years old, studying in $12^{\text {th }}$ standard while Mr B is 22 years old, studying in $2^{\text {nd }}$ year of engineering in Haryana, India.

Both brothers were brought by their parents with the complaints of insidious onset, gradually progressive excessive online gaming, irritability, decline in studies performance, and impaired self-care for the past 2 years. The problem began when both brothers used to stay together at home and started playing online game with their virtual Internet friends from different countries. Due to difference in GMT (Greenwich mean time) across all countries, they had no specific timing for games and hence the gaming interfered with their sleep and daily routine. The duration of online gaming progressed from 2 - 4 hours per day to 14 - 18 hours per day over the initial few months. The behavior and self-care of these brothers became so compromised and disorganized that while playing the games, they urinated and defecated in their clothes, did not change clothes for days, did not bathe, skipped their meals, did not pick up phones or open doors even to their parents. They were not concerned even when strangers entered the house in their 
presence and robbed the house. Their home was robbed twice of cash and costly articles in their presence, during the last 2 months while they were preoccupied in playing online games. They both failed in their respective classes last year although they were meritorious students. They shouted at parents, abuse and hit them and even locked in their rooms when stopped from playing game.

The patients were admitted in view of above problems, the severity of gaming addiction. Their general physical examination, systemic examination, and laboratory investigation were within normal limits. On interviewing, irritability, and craving for games was elicited. No psychotic symptoms were reported or elicited. The aim of the treatment was to reduce irritability, improve sleep, daily routine, and self-care along with enhancing motivation and reducing craving for online games to prevent future relapses. Diagnostic psychometric assessment revealed impulse control problems, depressive cognitions, and delinquency in both brothers.

Fluoxetine $20 \mathrm{mg} /$ day was started (increased to $40 \mathrm{mg}$ / day) along with clonazepam $0.5 \mathrm{mg}$ as required for sleep. Non-pharmacological methods were the main stay of management. It included limit setting, motivational interviewing, motivation enhancement therapy, activity scheduling, family and individual therapy, distraction techniques, and positive reinforcement using principles of behavior therapy. During the one month stay in the hospital, both patients improved considerably with reduced irritability and craving for online games, better self-care and hygiene, improved sleep, and interest in studies. The improvement maintained during the 6 months follow up, even after stopping fluoxetine with simple methods of behavior therapy using parents as co-therapists.

\section{Discussion}

Internet is undoubtedly a remarkable invention. When used properly with good intention, it has great technological value in research, communication, information, leisure activities, business transactions, and learning. However, there is always a dark side to new technologies. In case of Internet, it turns to an addiction which is a recent concept and still under research. Internet gaming addiction is the latest phenomenon in the world of Internet (5). For many adolescents, spending time on the computer means playing online video games. A market research company has estimated the China's worth online gaming market as $\$ 12$ billion in 2013. A recent review article reported prevalence estimates ranging from $0.2 \%$ in Germany to $50 \%$ in Korean teenagers (6).

Although Internet gaming disorder has not been classified under main disorders of DSM-5, researchers have realized that Internet gaming is increasingly being used by people of all ages, especially younger population, who may face severe consequences associated with compulsive use of games (6). According to DSM-5 (4), Internet gaming disorder refers to the "persistent and recurrent use of the Internet to engage in games, often with other players, leading to clinically significant impairment or distress as indicated by 5 (or more) criteria in a 12-month period." These criteria comprise lack of control over the use of Internet games, preoccupation with Internet gaming, psychological withdrawal, developing tolerance for games and need for increase use of games, loss of other significant interests, use of Internet games despite negative consequences, and significant decline in social and occupational domains $(4,6)$. All these signs and symptoms were observed or reported in the described case report of patients. Internet gaming addiction is a disorder that is most dramatically expressed with games known as massively multiplayer online games (MMOs) (7) and specially massively multiplayer online role-playing games (MMORPGs) like World of Warcraft (8). MMORPGs are games played by thousands of players at the same time (massively multiplayer). Because these games are played online, there are no spatial or temporal boundaries and they allow players to adopt various virtual roles. MMORPGs utilize the principles of operant conditioning by using highly reinforcing random reward patterns. Hence, these games are specially engineered to maximize the amount of time a player stays in the game. The same was observed in the patients where they used to play such games with virtual friends across different countries and at odd hours.

There is a growing concern about several negative consequences associated with Internet gaming addiction. The psychological consequences vary and include difficulty in real-life relationships, disturbances in sleep, work, education, socializing, attention, academics, and memory. It may include aggression and hostility, stress, and high loneliness (6, 9-11). Most of these disturbances were evident in both patients.

Considering the shared features with addiction disorders, which are evident from the above case, Internet gaming addiction could be placed alongside the main disorders in the future classificatory systems. DSM-5 needs to consider the severity classifiers for the disorder, which might present variedly depending upon the content and type of games, cultural context of gaming, and associated personality type. Internet addiction is a new and emerging group of disorders in Indian subcontinent (12). It has proliferated and spread across the subcontinent, in spite of deeply knit family systems and parental supervision. Systematic studies need to be undertaken in Indian subcontinent to evaluate the prevalence and type of gaming addiction. Crucial steps in curtaining this evolving epidemic must be taken in the form of legal limitations on sale/purchase, setting the age limit, and restricting access to online games.

\section{References}

1. Goldberg I. Internet addiction disorder (IAD)-Diagnostic criteria Retrieved Jan 3, 2011. 1995. Available from: www.psycom.net/iadcriteria.html.

2. Block JJ. Issues for DSM-V: internet addiction. Am J Psychiatry. 2008;165(3):306-7. doi: 10.1176/appi.ajp.2007.07101556. [PubMed: 18316427] 
3. Tanner L. Is Video-game Addiction a Mental Disorder? . Associated Press; 2007. Available from: http://www.msnbc.msn.com/ id/19354827/ns/technology_and_science-games/t/video-gameaddiction-mental-disorder/.

4. American Psychiatric Association. Diagnostic and Statistical Manual of Mental Disorders (DSM-5). Virginia; American Psychiatric Association. 2013.

5. Ng BD, Wiemer-Hastings P. Addiction to the internet and online gaming. Cyberpsychol Behav. 2005;8(2):110-3. doi: 10.1089/ cpb.2005.8.110. [PubMed: 15938649]

6. Kuss DJ. Internet gaming addiction: current perspectives. Psychol Res Behav Manag. 2013;6:125-37. doi: 10.2147/PRBM.S39476. [PubMed: 24255603]

7. Nagygyörgy K, Urbán R, Farkas J, Griffiths MD, Zilahy D, Kökönyei $\mathrm{G}$, et al. Typology and sociodemographic characteristics of massively multiplayer online game players. Int J Hum Comput Interact. 2013;29(3):192-200.
8. Kuss DJ, Louws J, Wiers RW. Online gaming addiction? Motives predict addictive play behavior in massively multiplayer online role-playing games. Cyberpsychol Behav Soc Netw. 2012;15(9):4805. doi: 10.1089/cyber.2012.0034. [PubMed: 22974351]

9. Kuss DJ, Griffiths MD. Internet gaming addiction: A systematic review of empirical research. Int J Ment Health Addict. 2012;10(2):278-96. doi:10.1080/10447318.2012.702636.

10. Batthyany D, Muller KW, Benker F, Wolfling K. [Computer game playing: clinical characteristics of dependence and abuse among adolescents]. Wien Klin Wochenschr. 2009;121(15-16):502-9. doi:10.1007/s00508-009-1198-3. [PubMed:19787320]

11. Shapira NA, Goldsmith TD, Keck PE, Khosla UM, McElroy SL. Psychiatric features of individuals with problematic internet use. $J$ Affect Disord. 2000;57(1-3):267-72. [PubMed:10708842]

12. Raju Srijampana VG, Endreddy AR, Prabhath K, Rajana B. Prevalence and patterns of internet addiction among medical students. Med J DY Patil Univ. 2014;7(6):709. doi: 10.4103/0975-2870.144851. 